\title{
LTTERATnRE.
}

1. Untertuchnngen über Baclerien, Bd. Il p. 118 (Belts. 2 Blol. d. Phismen, 1855, Heft s).

2. Lebrbuch der path. 355ologic, 1800, p 875 .

3. Annal de 1'Inst. Pastenr, 1858, tome ti. p 225.

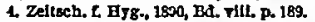

5. Ann. de mlcrograph., Parte, 1890. p 419.

6. Beltrig. zur path. Anat. nad zar allgem. Path, 1890, Bd, clil. nnd ziv, pp. 287-328.

7. Junch. med. Wochenschrth, Seplember 15, 189t, p. 65 .

8. Annall del. Ingt. d'Iglene eper. d. Fniv. dl Roms, 1892 rol. 1. p. 42.

9. Annal. de l'Inst. Pastenr, 1892, tome vl. p. 265.

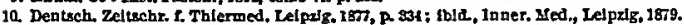

11. Beltrig. 2 patb. Anst, etc., 1890, Bd. ix.

12 Virehow's Archls, Bd. CrIIvl, p. 69.

18. Ceniralbintt C. Bak., Bd. xTrl. p. 187.

14. Annal, de l'Inat, Fastenr, 1890, thme xill. p 841.

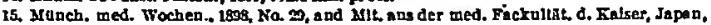
Unlversit. 20 Tot:la, Bd, Ir. Nin. 7, p. 28l.

16. Junknal nf Experimeitthl Nediclice, 1001, vnl จ. p. 155 .

17. Iondon Isancet, 1899, rol, IL. P. 779 .

18. Verhand. d. Cong. I. Inner. Med., ud, Iv, p. 351.

19. Jnnmal of Expertmental Mediclne, 1898, Non, 4 and 5 , vol. ill. p. 122

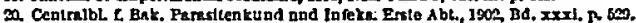

21. Berlln tilin. Wochen., 1895, B4. xexil, pp. 735, 765, 786. .

22. La presse med., Septezuber 22, 1801, p. soe.

23. Annal. de l'Iast Pasteur, 1896, torne vill. p. 139.

31. Chicago Hedical Record, June, 1900.

\section{ASSOCIATED MOVEMENTS OF THE HEAD AND EYES IN} INFANTS. ${ }^{1}$

\author{
By Sasroer McC. Hasill, MI.D., \\ AND \\ Willahir Casipbeli Posey, M.D., \\ or rmunzepith.
}

The various forms of movements of the head and eyes in infants -the so-called rotary and nodding spasms of the head and vertical, horizontal, and rotary nystagmus-are observed quite commonly. The obscurity of their origin makes them especially interesting. For this reason Dr. Posey and I have decided to present these three cases, which happen to be attending our services in the Howard Hospital at the present time.

CASE I. - Carl C., aged three years, first came to the children's elinic in the Howard Hospital on Oetober 13, 1903. The history recorded at that time was as follows: His birth was normal, and his first dentition complete. His parents are living and well, save that his mother is thought to be nervous. He has no brothers nor sisters, and his mother has had no miscarriages. His previous health has been excellent. He has had none of the infectious diseases of

1 Read before the Philadelphis Pediatre Soclety, Aprl 12, 1901. 
childhood, and has never had any convulsions. For some time be has complained of abdominal pain. For many months he has lived chiefly on two cups of weak tea with each meal, milk, hread, and butter. He never eats meat. He eats freely of ice cream, but of other sweets rirely.

The condition which hrought him to the dispensary was a cough of two days' stamling wluch was accompanied by fever at night. The cough laal a tendency to be paroxysmal, and the paroxysms were sometines severe; it was tight, and there was no expectoration. He hal some epigastric pain, and his bowels had been loose for several dnys. He hal several stools each day, which were yellowish and witery, but contained neither blood nor mucus.

The physical examination showed a well-nourished child. His tongue was heavily coatel, and its papillne red and prominent. His frontal and parietal eminences were prominent; there was moderate thickening of the epiphyses at the wrists and ankles. There was some costochondral thickening and some retraction of the base of the chest, more marked on the right side; there was moderate dorsolumbar lordosis and decided outwand bowing of the tibiz. His abdomen was prominent; its walls flaccid, and there was marked separation of the bellies of the recti. His spleen was not palpable; but his liver was felt a finger's brendth above the transverse umbilical line, about three inclies to the right of the umbilicus. There were a few scattered moist rales over each lung. He had a fairly loud, low-pitched, blowing systolic murmur, best heard in the aortic area and transmitted especially well to the top of the sternum and into the suhclavians, less well into the carotids. A murmur of similar character was heard over the body of the heart, at the apex, in the axillary region, at the angle of the scapula, and in the interscapular space. At the apex the murmur was the same in character as that lieard at the base, but in this area it seemed to occur later in systole; the second sound was beard distinctly over the upper chest.

On November 15th he had a mild follicular tonsillitis. On March 10, 1904, he was brought to Dr. Posey's clinic in the Howard Hospital on account of movements of the head and eyes and reduction in vision. These manifestations were first noted early in December. They had increased persistently up to this date. The liead movements were lateral and not constant, the bead apparently being drawn to the right and the chin slightly elevated, as if by action of the left sternocleidomastoid muscle. The eye movements were also from side to side and constant, the excursions being fairly extensive.

He was unable to recognize objects at a distance of four or five feet, but when bronght within this range they could be defined. Any attempt at fixation caused a decided increase in the excursions of both the bead and eye movements, especially the latter. Covering the eyes produced a temporary cessation of the movements of 
the head, and they ceased during sleep. There was some restriction to the movements to the right in hoth eyes.

An examination of the eye-ground hy Dr. Posey showed some engorgement of the veins, hut no other ahnormality. The only. other nervous phenomenon noted was a slight uncertainty in his gait, and a mild ataxia, which had never heen sufficiently marked to attract the father's attention. His reflexes were normal.

Further questioning slowed that in Decemher he had had a slight disclarge from one ear, which cleared up quickly. Ahout the same time lie developed a cough, which has persisted. He has occasional severe paroxysms, which the father says sound like. whooping-congh. Usually it is loose, but without expectoration. He vomits during or immediately after almost every meal. He does not seem to he nauseated, and frequently eats immediately after vomiting without heing sickened. He never vomits at other hours of the day. His howels continue loose-four or five stools each day - which are watery and yellowish in color. He voids urine frequently and in large quantity. Two examinations of the urine showed nothing ahnormal, except a lowered specific gravity -1014 and 1012. Dr. F. R. Packard kindly examined the ears, throat, and nose, and reported notbing abnormal.

CASE II.-R. E., aged seven months, came to the Howard Hospital Dispensary on March 24, 1904. His birth was normal; his parents, three hrothers, and one sister are living and well. One hrother died aged two years of "hahy consumption." He has had no convulsions, no manifestations of syphilis, and no previous illness. He has heen fed exclusively on the hreast ahout every third hour.

$\mathrm{He}$ was hrought to the dispensary on account of a coryza of one week's duration; the discharge was free, and consisted of thin mucus without hlood. His respirations were snoring in character -a condition which had existed since hirth. There were no evidences of sore throat, but he had a cough in the heginning of the attack which was croupy in character. He has had no gastrointestinal symptoms.

The mother first noticed shaking movements of his head and eyes between the third and fourth months, and for some time he has had profuse head sweating. He is thought to have gained steadily in weight. He has always been a mouth-hreather, and constantly chokes while nursing, as if there was some ohstruction to nasal hreathing. He secmed quite hright; and had no fever.

The physical examination showed a fairly well-nourished infant. There was no evidence of nasal memhrane. His urula was swollen and red. The fauces and tonsils were red, hut without exudate. His tongue was moderately coated. His head was narrow in the hitemporal diameter, and the posterior fontanelle was still open. The coronal, sagittal, and lambdoidal sutures were wide open, and there was marked craniotabes along the horders of the squamo- 
parietal and mastoparietal sutures, especially evident on the right side. He had a bald spot over the occiput. His neck was short, and the sternum elevated. His clavicles were on a direct plain with the body, and probably elevated slightly at the sternoclavicular junctions. His chest was markedly violin-shaped, his costochondral junctions were much enlarged,- suggesting on palpation a backward dislocation of the cartilages. The portion of the chest wall between the costochondral junctions was pusbed forward. The epipbyses wcre thickened at the wrist and knees, and there was slight dorsolumhar kyphosis. His abdomen was prominent, the bellies of the recti muscles nere separated, and there was some pouting of the umbilicus. He bad a frequently recurring spasm of the muscles of the back of the neck, with retraction of the head. Similar muscle spasms were not noted in other groups. His inguinal, axillary, epitrochlear, suhoccipital, postcervical, and a few of his deep cervical glands were enlarged. He had marked lateral and tilting to-and-fro movements of the head, the head rotating to both sides as if by alternate contractions of the sternocleidomastoid muscles.

Dr. Posey's report upon the eye condition showed "lateral nystagmic movements with very short excursion and of similar extent in each eye. There were no apparent ocular palsies. On near fixation the movements were much increased, and this was associated with increased movements of the head. The examination of the eye-ground showed nothing ahnormal."

On April sth it was noted that the infant had emaciated decidedly, although his general condition seemed better; his head and eye movements were less.

CASE III.-Lilian B., colored, aged eleven months, applied for treatment at the Howard Hospital Children's Dispensary on August
13,1902 . Her birth was normal.

Family History. Both parents are living and well, but a paternal aunt and uncle died of phthisis. The child had had no previous disease, but had always been "poorly." She had heen hreast-fed for the first four weeks of life, since which time she bad been fed on cows' milk, bread, crackers, cakes, candy, ice-cream, chocolate, and potatoes. Slie was brought to the dispensary for a cough, which she had had for tbree or four months. Sbe was sometimes feverish, and had occasional night-sweats. Her cougb was most severe at nigbt. Her bowels moved six or seven times a day, the stools being yellowish in color, very loose, malodorous, and containing curds, but no mucus.

Physical Examination. The child was emaciated. The anterior fontanelle was very large, the sutures open, and the posterior fontanelle still open. The chest was markedly violin-shaped, and there was beading of the ribs. There was some epiphyseal thickening, the abdomen was very prominent, the umbilicus pouted, and there was separation of the bellies of the recti muscles. The 
HAMIILL, POSEY: MOVEMENTS OF THE HEAD AND EYES. 879

heart's action was regular and rapid, and the sounds clear. The breathing was labored, and the respiratory movements were increased in frequency. There were no areas of dulness. There was a wheezing sound on inspiration. The chest was full of sibilant and sonorous rales, hy which the respiratory murmur was masked. There were no areas of bronchial breathing. The spleen was palpable just below the costal margin, and the liver one-half inch helow. The cervical, anterior and posterior, the axillary and inguinal glands were moderately enlarged. The hody temperature was normal.

The child made three return visits from this time up to the middle of October, 1902, and then disappeared until February 24, 1903. She was hrought back on account of the return of the cough of the previous winter. She had recently had an otitis media on the left side. At the time she returned she was having a great deal of nasal discharge. Her appetite was poor, her cough loose, and attended by considerable expectoration. She slept well, hut sweated a great deal about the lead at night. It was noter at this time that she bad a marked lateral nystagmus, which was said to have existed since the third month. It was much more marked in the right eye, and was at first thought to bave been unilateral. Thcre was no history of head movenients at any time, nor of muscular twitchings in any other part of the holly. At the age of sixteen months she had only her upper and lower middle incisor teeth. The anterior fontanelle was as large as a dollar, and the sutures were separated some distance from the fontanelle. There was marked howing of the hones of the foream, eversion of the legs, without much bowing of the hones, except a slight anterior howing of the tibire. The spleen was palpahle a finger's breadth helow the costal margin. The child was very weak, and required considerable assistance in order to maintain an erect posture. There rere a few rales over the chest. The physical examination otherwise showed no changes.

Following this the child was absent from the dispensary for about eight months; when she returned with an aphthous stomatitis. Five months later she returned suffering from prolapse of the rectum. She was having three or four stools daily, accompanied by straining. They contained mucus, and there had been a slight amount of blood in some stools. This developed sometime after the prolapse of the rectum. Prior to this time the bowels had heen normal. The abdomen was very much distended. There was no vomiting. The spleen was not palpable, the liver was two inches below the costal margin. There was no evidence of prolapse of the rectum found on examination.

The child-returned twice following this, the last time on March 30th, on which occasion it was announced that there was no longer any prolapse of the bowel. A careful physical examination showed nothing to account for the prolapse. She had never vomited. She had no abdominal signs of any significance. 
She is twenty-six months old at the present date. Her eye and stomach teeth are just erupting. All of her teeth are in poor condition and immaturely developed. One lower incisor has been lost by heing caught in the thread of her skirt, indicating that the attachment of the teeth is insecure. The examination of the eye condition hy Dr. Posey shows that when at rest the nystagmus is limited to the right eye; the movements are lateral, and the excursions very short. On fixation, or when the eyes are removed from the primary positions, slight nystagmic movements appear in the left eye also. There does not seem to he any limitation in the movements of the eyeball in any direction. Once or twice during examination, when the attention was suddenly attracted, there was a marked vertical vihrating spasm of the upper lids. Excitement increased the nystagmic movements, hut the movements were not increased when the head was held fixed.

The question of the etiology of these phenomena remains unsettled. Numerous theories have been advanced, and the more recent writers have been in some accord in relation to this point. That the condition is dependent upon some functional disturbance of that part of the nervous system controlling the movements of the head and eyes is generally conceded. While it is not our purpose to treat this subject exhaustively it may be well to briefly review some of the more important theories that have been suggested.

Predisposing Causes. Age is an essential predisposing factor, the vast majority of cases occurring between the ages of two and twelve months, although Gee has reported a case occurring as early as the sixth week, and Henoch one as late as the third year. The cases are pretty evenly divided among the sexes with a slight
majority in favor of females.

Hercdity is supposed to play some part, in that a number of cases have occurred in families of bad nervous history, including epilepsy. Rickets is probably the most common predisposing factor. In his early series of cases Hadden found this condition present in but two of eleven. On the basis of this finding he attached but little importance to it. In his second series of nine cases he found it present seven times, after which he modified his views decidedly. Other authorities differ as to its etiological relationslip, the majority considering it an extremely common factor. The remarkahle frequency of rickets, especially of its milder fonns, would lead us to believe that its association has prohably been closer than statistics would indicate. We are of the opinion that the milder manifestations of rickets, the head sweating, delayed dentition, and moderate heading of the ribs, but more especially the muscle and nervous phenomena, are of very frequent occurrence, and that, because we are prone to depend upon the skeletal deformities for our diagnosis, the manifestations in the nerrous system-irritability, night terrors, etc.-and the muscle phenomena-pot-helly, gastric and intestinal 
distention, constipation, etc--are apt to pass unrecognized. In the dozen or more cases seen by one of us rickets of some degree was manifest in each.

Exciting Causes. Dentition. was thougbt by Henoch to be the most common, becuuse the conditions occurred during the period of first dentition, and because in some of his cases its beginning was coincident with the eruption of some of the first set of teeth. Most authorities admit that it may act as a contributing cause, but that it does not occupy the important position attributed to it by Henocb is manifest from the fact that many recorded cases bave occurred at an age whicb would eliminate the teeth as a disturbing element.

Gastrointestinal irritation bas preceded its occurrence in many cases, and it is generally conceded to be an important factor. It may act either reflexly or througb the medium of toxic products absorbed from the intestinal tract.

Traumatism was recorded in a number of Hadden's cases,' and in those of Peterson and Hirsch. Peterson tbinks it probable that concussion is the determining factor in most cases- "a concussion setting upin the centres of the spinal accessory, and at times in those of the oculomotor nerves, an arrbythmic discharge."

Our knowledge of the pathology of these movements, for obvious reasons, is mainly speculative. Hugblings Jackson considered the condition a variety of "spinal system chorea, a symptomatic condition akin to canine chorea," while Gunn believed it was in some way associated with epilepsy, basing his view upon the quite common occurrence of temporary loss of consciousness in these cases, and the presence of epilepsy and other nervous conditions in the families in whicb they occur. Henoch previously suggested the same view, and Hadden, whose cases were the basis of Gunn's suggestions, gave this opinion some consideration.

Henoch, in describing his cases, suggested that the concomitant existence of these bead-and-eye movements "seem to indicate that the root nuclei of the spinal accessory and of the upper spinal nerves supplying the affected muscles of the throat and neck stand in a very close relation to those of the ocular nerves (occulo-motorius)," a relationsbip wbich has since been definitely determined. Hadden believed that "the seizures pointed to instability of motor centres above the nuclei in the spinal cord and fourth ventricle, therefore attributing the disorder to a functional or otber disturbance of the cerehral cortex. The child has acquired certain voluntary or purposive movements of the head and eyeballs, but these bave not as yet become thoroughly organized and fixed in the psychomotor areas of the brain, bence a dissolution takes place because of the inahility of the strained cortical centres to stand the work to which they bave been too early suhjected." This opinion, quoted by Mills, is one which be believes "throws the best ligbt on an obscure subject." 
Aldrich, in his very ahle discussion of this condition, voices the same view as to the nature of the condition. As we have stated, while we are hy no means certain that the nature of these conditions is dcfinitely determined, we incline to accept Hadden's explanation.

These threc cases differ to some extent in the character of the head and eje movements. In Case III. the head movements are lacking entirely, the nystagmus is mainly in the right eye, and, according to the mother's statements, has existed since the third month. A point of special interest in this case is the occurrence of the vertical movements of the upper eyelid on an attempt at sudden fixation, a feature which has been noted but once hefore.

In Case II. the movements began at a very early period-between the third and fourth months-and involved both the head and eyes. They were equal on both sides. There was present in this case an intermittent spasmodic contraction of the muscles of the back of the neck.

In Case I. the movements began at an unusually late periodafter the timc that such movements have ordinarily disappeared. The head movements in this case are caused mainly by spasmodic contraction of the left sternocleidomastoid muscle, and the eye movements are the same on the two sides. In addition, there is some crident defect of vision and a slight ataxia, a somewhat similar condition having been noted in one of Hadden's cases. This is the ouly case in which it was possible for us to demonstrate any limitation in the excursions of the extraocular muscles.

Strabismus was not noted in any of the cases. There have been no antecedent nerous conditions from which the head and eye movements might have resulted, and none of them have had any of the acute diseases of childhood except Case I. The pupils were of normal size and reacted normally in all three cases, nor were there any changes in the fundi other than the dilatation of the retinal veins noted in Case $I$. The eyes in all three cases were moderately hypermetropic.

While the head-and-eye movements are manifested in a somewhat different way in eacl of these cases, and while we have heen unable to elicit a history of head movements in one of them, we are, nevertheless, of the opinion that they are all dependent upon some form of irritation of the cortical areas.

The extreme rachitic manifestations present in all the cases marks this condition as the underlying or predisposing factor. The exciting cause in Cases II. and III. are difficult to determine. They both developed before the age of dentition, there is no history of injury, and they did not suffer from acute diseases which might have acted reflexly or by the development of some toxic irritant, or hy suddenly producing increased instability of the motor centres, from the resulting exhaustion. The early age at which they became 
manifest and the striking, rachitic condition which was preseut lead us to helieve that the toxic products resulting from the disturhed metaholism due to the rickets were the irritating factors in these cases. In Case I., however, the conditions are different. The rachitic manifestations in the child were much later, hut very marked, quite sufficient to interfere with the nutrition of the nervous system.

The movements hegan in this case ahout two weeks after an attack of hronchitis, which was associated with diarrhoa, the latter condition persisting up to the present time. Furthermore, this child has heen partaking most intemperately of tea for many months, regularly drinking two cups with each meal. The hronchitis, diarrhoea, and tea drinking, therefore, acting in a markedly rachitic child, we consider quite sufficient to have produced the phenomena noted.

A point of interest in these cases is the relationship which exists hetween the movements of the eyes and head. In an article which was read hy one of us hefore the fifty-third annual meeting of the American Medical Association, entitled "Associated Movements of the Head and Eyes," the close association which exists physiologically between the movements of the head and cyes was dwelt upon, and it was shown how the head hy its movements augments the range of the field of vision and supplements the action of the extraocular muscles in the delicate task of maintaining proper visual axes. Attention was also called to the fact that in order that the head may properly perform this twofold task it is provided with numerous and intricately acting muscles, and it is only when one considers that there is scarcely a position assumed hy either the eyes or head in which the action of hoth parts does not enter that one realizes how intimate the relationship hetween the extraocular and cervical muscles is.

To facilitate the study, all associated movements which exist between the head and the eyes were divided into four groups. The first group referred to movements which are physiologic and will require no further mention here. The second group included ahnormal simultaneous hut independent movements, such as occur, for example, in disseminated sclerosis, where the movements which are ahnormal and often simultaneous and have the same pathogenic origin are not related in the sense of being dependent upon one another. The third group dealt with compensatory movements. To this class were relegated cases which assumed a vicarious position of the head to compensate for some imperfect action of one or more of the extraocular muscles, such, for example, as occur after paralysis of one or more eye muscles. The fourth group referred to related hut not compensatory movements, and included movements of the head and eyes which are ahnormal and hear a distinct relationship to one another without heing dependent upon 
one another. Cases of head-nodding in children, such as have heen presented to the Society to-night, were included under this latter group, although it was realized that there are a numher of reasons why they should have been placed under the third group and the movements of the head considered to he secondary to those of the eyes. Thus, it is a well-estahlished clinical fact that movements of the head, apparently similar to those ohserved in this class of cases, may originate in children whose eyes oscillate as a consequence of lowered vision, occasioned by a disense of the eyes, and it has heen noted not infrequently that nystagmic adult patients hold their beads in a peculiar position while fixing for hoth distant and near ohjects, and often succeed in steadying the oscillation of the eyeballs in this manner. It has been remarked, too, in cases of the affection under discussion, by hoth Raudnitz and Caille, that if the eyes are handaged the motion of the head censes. Raudnitz noted also, in common with otber observers, that the bead movements were much influenced by the deviation of the visual axes, tbat they ceased wben the eyes were deviated in certain directions, and started up again as soon as tbey were rotated from this position. This writer tbought that the disease was particularly apt to arise in the dark winter months and to affect those confined in darkened rooms, bclieving that the head-jerking was secondary to the nystagmus, the latter being occasioned by strain upon the eyes consequent upon the infant's constant attcmpt to look toward the windows. Notwithstanding these observations and the wellestablisbed fact of the possihility of movements of the bead being inaugurated by those of the eyes, it is probable tliat such is not the case in bead-jerking, the movements occurring in association by reason of a common cause affecting the centres controlling each simultaneously, but without being dependent upon one another.

While in most instances the data which have heen gatbered regarding the time of the occurrence of the nystagmus and of the head-jerking are obtained hy questioning the parents, and are, therefore, not entirely reliahle, still there is evidence to show that the nystagmus does not always precede the head-nodding, that the head-nodding may even he observed some weeks or months before the jerking in the eye muscles manifests itself, and that, finally, head-jerking may occur without the occurrence of nystagmus during the entire course of the disease.

Moreover, in order that the movements of the head should compensate and neutralize those of the eyes, they should he directly opposite to one another; sucl a condition, bowever, has been found in but one case, the motion of the bead being either in the same direction as those of the eyes, or, what is more usual, without any connection with them whatsoever. Again, the movements of the eyeballs are usually twice as rapid as those of the head and have their own rhythm. 
It has been suggested that the presence of a strabismus in some of these cases would indicate that the nystagmus, under such conditions, at least, was the primary factor, but while the strabismus may indicate a palsy of one of the eye muscles nystagmus does not follow palsy of the eye muscles under other conditions.

\title{
A STUDY OF A CASE OF SPLENOMIYELOGENOUS LEUK AMMIA.
}

\author{
By Alexander Hasmeton Peacock, M.D., \\ HODaE gUBOEON, MOATS TLTLOB nOSPTTLL, BCRNTON, PL. \\ (From tho medical service of Dr. Walnoright.)
}

THE subject of this study was previously under the care of Dr. J. Emmet O'Brien, of Scranton, and Dr. Tbompson, of Carbondale, to both of whom we are indebted for notes of his former history.

The patient stated that about six years before admission to the hospital he had a severe attack of abdominal pain, with vomiting and diarrbee. He said that this illness was similar to his subse quent ones. He was given arsenic at the time, and made a good recovery, and was apparently in good health until late in the year 1902, except for a timc in 1901, when he was bothered. by a pain in the splenic area.

About October, 1902, lie began to suffer again with "bloating" and with alternate constipation and diarrhoa. Dr. O'Brien first saw him on December 11, 1902. He found the spleen much enlarged. A record of the blood count was not kept, but it is known that the leukocytes were much increased in number, and smears sbowed the picture of a leuksemia of the splenomyelogenous type. Fowler's solution in increasing doses was prescribed. On January $3 d$ the patient returned much improved, and the splenic tumor was not palpable. On January 28th the spleen could again be felt, and the leukocytes were still numerous. His general condition, bowever, seemed to be improved. He was last seen by Dr. O'Brien on March 24, 1903.

From Marcb, 1902, until his admission to the bospital he was seen a few times by Dr. Thompson, who was called chiefly for gastrointestinal trouble. One of these attacks yielded to small doses of calomel daily. At another time be was again given arsenic, with benefit.

On the whole, during this period his condition was fairly good, He seems to have been troubled only by the attacks of diarrhcea, and he kept very steadily at his active duties as inside foreman of a coal mine until March 31, 1904. 